\title{
Papers
}

\section{Crotaline snake bite in the Ecuadorian Amazon: randomised double blind comparative trial of three South American polyspecific antivenoms}

\author{
Roger Smalligan, Judy Cole, Narcissa Brito, Gavin D Laing, Bruce L Mertz, Steven Manock, Jeffrey Maudlin, \\ Brad Quist, Gary Holland, Stephen Nelson, David G Lalloo, Gonzalo Rivadeneira, Maria Elena Barragan, \\ Daniel Dolley, Michael Eddleston, David A Warrell, R David G Theakston
}

\begin{abstract}
Objective To compare the efficacy and safety of three polyspecific antivenoms for bites by pit vipers.

Design Randomised double blind comparative trial of three antivenoms.

Setting Shell, Pastaza, southeastern Ecuador.

Participants 210 patients with incoagulable blood were recruited from 221 consecutive patients admitted with snake bite between January 1997 and December 2001.

Intervention One of three antivenoms manufactured in Brazil, Colombia, and Ecuador, chosen for their preclinical potency against Ecuadorian venoms.

Main outcome measures Permanent restoration of blood coagulability after 6 and 24 hours.

Results The snakes responsible for the bites were identified in 187 cases: 109 patients (58\%) were bitten by Bothrops atrox, 68 (36\%) by B bilineatus, and 10 (5\%) by B taeniatus, B brazili, or Lachesis muta. Eighty seven patients (41\%) received Colombian antivenom, $82(39 \%)$ received Brazilian antivenom, but only 41 $(20 \%)$ received Ecuadorian antivenom because the supply was exhausted. Two patients died, and 10 developed local necrosis. All antivenoms achieved the primary end point of permanently restoring blood coagulability by 6 or 24 hours after the start of treatment in $>40 \%$ of patients. Colombian antivenom, however, was the most effective after initial doses of $20 \mathrm{ml}$ (two vials), $<70 \mathrm{ml}$, and any initial dose at both 6 and 24 hours. An initial dose of $20 \mathrm{ml}$ of Colombian antivenom permanently restored blood coagulability in $64 \%(46 / 72)$ of patients after 6 hours ( $\mathrm{P}=0.054$ compared with the other two antivenoms) and an initial dose of $<70 \mathrm{ml}$ was effective at 6 hours $(65 \%$, $\mathrm{P}=0.045)$ and 24 hours $(99 \%, \mathrm{P}=0.06)$. Early anaphylactoid reactions were common $(53 \%, 73 \%$, and $19 \%$, respectively, for Brazilian, Colombian, and Ecuadorian antivenoms, $\mathrm{P}<0.0001$ ) but only three reactions were severe and none was fatal.

Conclusions All three antivenoms can be recommended for the treatment of snakebites in this region, though the reactogenicity of Brazilian and Colombian antivenoms is a cause for concern.
\end{abstract}

\section{Introduction}

Each year in Ecuador, 1200-1400 cases of snake bite are reported in 19 of the 21 provinces. Reports from Santo Domingo de los Colorados, Guayaquil, ${ }^{1}$ and Shell ${ }^{2}$ confirm its importance. In "El Oriente," east of the Andes, the principal venomous species are Bothrops atrox (common lancehead) and $B$ bilineatus smaragdinus (two striped forest pit viper, also known as Bothriopsis bilineata smaragdina). B taeniatus (speckled forest pit viper, also known as Bothriopsis taeniata), the less common Bothrops and Bothrocophias species and Lachesis muta (bushmaster) cause some bites. ${ }^{34}$ The indigenous Amerindian peoples and people of mixed European ethnicity, whose occupations include farming and logging, are all at risk of snake bite. The principal clinical effects of envenoming by $B$ atrox are life threatening bleeding and blood coagulation disorders, shock, and renal failure. Necrosis and bacterial infection at the site of the bite may cause permanent physical handicap. Envenoming by $B$ bilineatus is usually less severe. Other species such as $B$ brazili and $L$ muta, although potentially as dangerous as $B$ atrox, rarely bite people. ${ }^{4}$

In an earlier preclinical laboratory study, the neutralising potency of five antivenoms (Brazilian, Ecuadorian, Mexican, and two Colombian) was tested against the venoms of $B$ atrox, $B$ asper, and $B$ xanthogrammus. ${ }^{56}$ The Brazilian antivenom proved most effective, followed by the Ecuadorian and two Colombian antivenoms. The Mexican antivenom showed absolutely no neutralising activity against Ecuadorian Bothrops venoms, consistent with its poor clinical reputation in Ecuador. ${ }^{5}$ We selected the three most effective antivenoms for a double blind randomised comparative clinical trial in Ecuador.

The main lethal effect of the venoms of the crotaline (rattlesnake-like) pit vipers responsible for envenoming is intracranial or gastrointestinal haemorrhage resulting from vascular endothelial damage, platelet dysfunction, and consumption coagulopathy. These dangerous antihaemostatic disorders and their reversal by specific antivenoms are reflected by whole blood coagulability, which is easily assessed at the bedside with a simple but sensitive 20 minute whole blood clotting test. ${ }^{78}$ We therefore used this test to measure the efficacy of the three antivenoms in restoring whole blood coagulability and observed early reactions to assess safety.

\section{Methods \\ Participants}

During the five year period January 1997-January 2002, patients of any age who presented with a history of snake bite at any time during the day or night to Hospital Vozandes del Oriente, Shell, Pastaza, Ecuador, were considered for the study, unless they had 
received antivenom within the previous 6 hours. Patients were included if the result of the blood clotting test showed that their blood would not coagulate. ${ }^{78}$ Patients or their relatives gave informed consent for admission, investigation, and treatment. All patients were admitted to the hospital and kept under observation for at least 48 hours. History, physical examination, and other relevant details were recorded on standard proformas. All members of the medical team were involved in the study, providing 24 hour cover.

\section{Antivenom treatment and randomisation}

We randomised patients in blocks of six to treatment with one of three antivenoms ${ }^{5}$ : Suero Antiofidico (Instituto Nacional de Higiene y Medicina Tropical "Leopoldo Izquieta Perez" Guayaquil, Ecuador); Soro Antibotropico (Instituto Butantan, San Paulo, Brazil); and Antiveneno Polivalente (Instituto Nacional de Salud, Bogota, Colombia).

The expiry dates of all the antivenoms used was December 2000 but from January 2001 until the end of the study, the Bra-

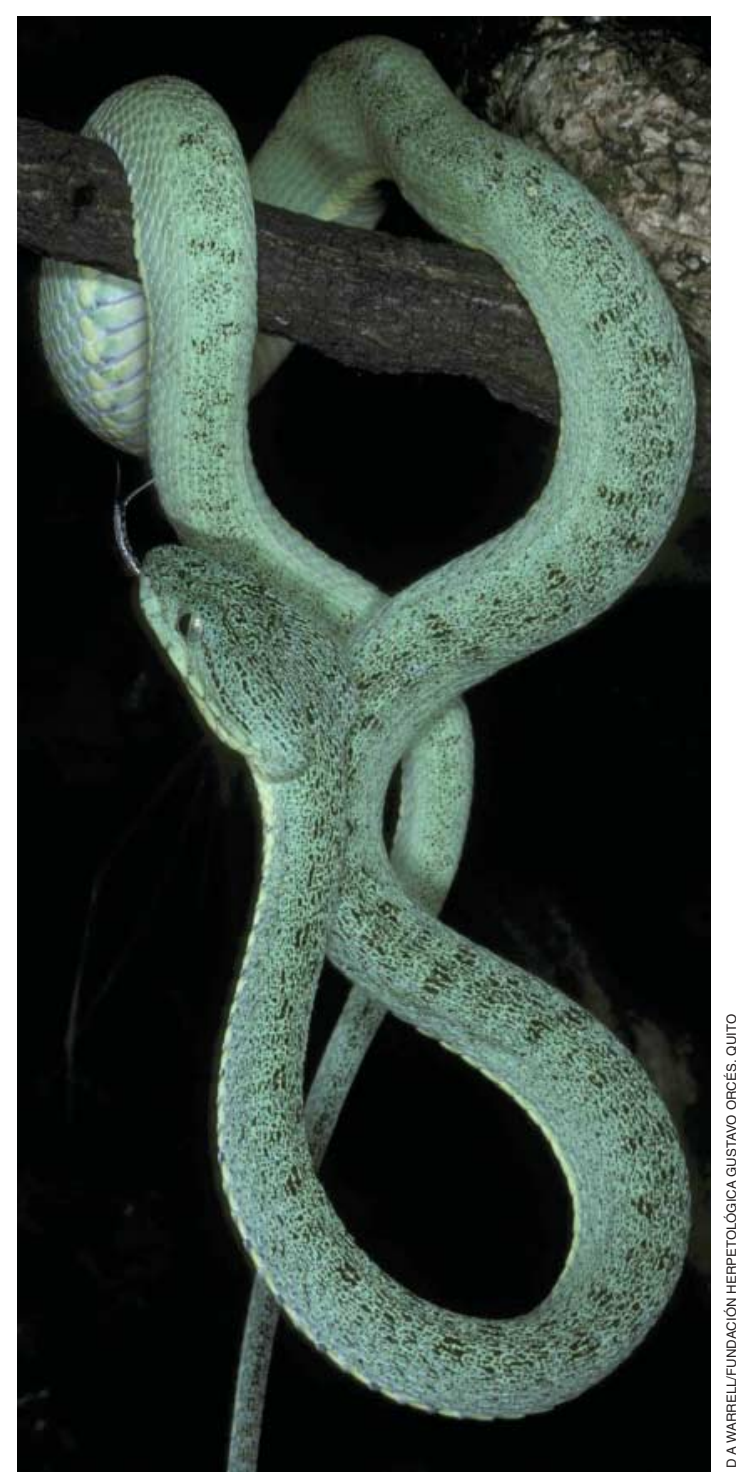

Two striped forest pit viper (Bothrops bilineatus smaragdinus, also known as Bothriopsis bilineata smaragdina) from Napo Province, Ecuador, within the catchment area of this study. As many as $36 \%$ of our patients had been envenomed by this species

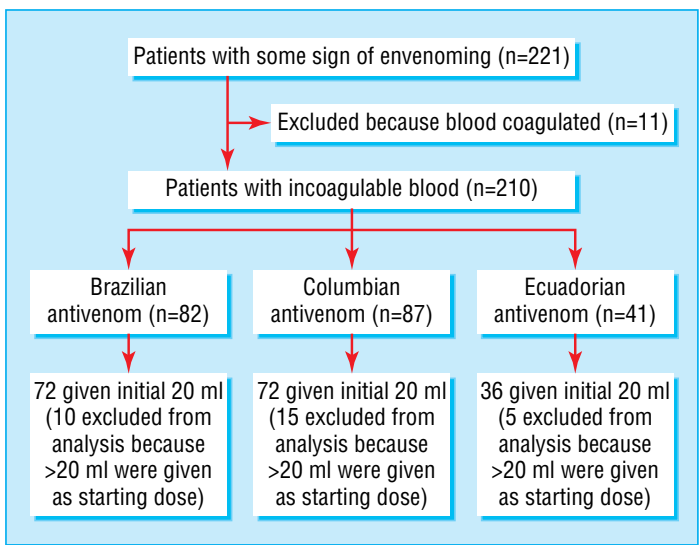

Fig 1 Flow of patient through study

zilian and Colombian antivenoms remained clear solutions and their in vivo neutralising potencies were undiminished..$^{10}$ By this time the Ecuadorian antivenom had already run out (see below).

We calculated that we would need to recruit 100 patients to each arm to detect an increase from $50 \%$ to $73 \%$ in the proportion of patients with clotting blood at 6 hours ( $80 \%$ power). After the 140th patient, the supply of Ecuadorian antivenom ran out, but strict randomisation was maintained to either Brazilian or Colombian antivenom. Allocation was determined by a table of random numbers. The antivenoms were packaged in numbered envelopes. The nurse on duty was responsible for drawing up the antivenoms, all indistinguishable colourless solutions, into an unmarked syringe so that the medical staff treating and assessing the patient and the patient were effectively blinded.

Most patients received an initial dose of $20 \mathrm{ml}$ (two vials) of antivenom by intravenous injection over 10 minutes. A minority, considered on admission to be severely envenomed, were given higher initial doses of up to $70 \mathrm{ml}$ (seven vials). Six hours after the start of antivenom treatment, we checked blood coagulability using the 20 minute clotting test. If the blood was still not coagulable, we administered a second dose of $20 \mathrm{ml}$ of antivenom. Further doses were given at every six hours until blood coagulability was restored permanently.

\section{General treatment}

All medical staff responsible for administering antivenom were familiar with the signs of early anaphylactoid reactions and watched the patients carefully for such signs. These were treated with subcutaneous adrenaline (epinephrine) and intravenous diphenhydramine and hydrocortisone, as was the current practice in Ecuador at the time of the study. Pain was treated with oral paracetamol, intravenous pethidine, or tramadol. Patients received fresh compatible HIV negative blood if their packed cell volume fell below 20\%, and routine tetanus prophylaxis was given. Local necrosis was treated by immediate surgical debridement, gentamicin, and chloramphenicol.

\section{Snakes responsible for the bites}

Dead snakes brought to the hospital were labelled and preserved in $10 \%$ formalin or $70 \%$ ethanol. They were formally identified at the Fundacion Herpetologica Gustavo Orcés in Quito.

\section{Laboratory investigations}

Venous blood was sampled on admission, at 6, 12, 18, and 24 hours later, and then daily until patients were discharged from hospital. Blood coagulability was determined by the 20 minute clotting test. We obtained background levels of absorbance in the enzyme immunoassay from blood samples taken from 100 rela- 
Table 1 Comparison of groups of patients bitten by snakes in Ecuador, at randomisation before treatment with antivenom*

\begin{tabular}{|c|c|c|c|}
\hline & Colombian ( $\mathrm{n}=87$ ) & Brazilian ( $n=82$ ) & Ecuadorian ( $n=41$ ) \\
\hline Mean (SD) age (years) & $28.3(18.4)$ & $27.3(17.1)$ & $23.3(15.6)$ \\
\hline Age range (years) & $2-80$ & $4-62$ & $4-54$ \\
\hline Male/female & $39 / 48$ & $42 / 40$ & $25 / 16$ \\
\hline Mean (SD) time between bite and antivenom (hours) & $6.8(9.1)$ & $8.3(14.6)$ & $8.4(10.7)$ \\
\hline Range of time before antivenom (hours) & $0.2-51$ & $0.2-102$ & $0.3-40$ \\
\hline \multicolumn{4}{|l|}{ Site of bite: } \\
\hline Foot/leg & 47 & 34 & 20 \\
\hline Hand/arm & 32 & 40 & 18 \\
\hline Other & 6 & 6 & 2 \\
\hline Snake species identified & 74 & 76 & 37 \\
\hline \multicolumn{4}{|l|}{ Snake brought with patient: } \\
\hline$B$ atrox & 5 & 7 & 1 \\
\hline$B$ bilineatus & 7 & 4 & 1 \\
\hline B taeniatus & 1 & 0 & 1 \\
\hline Unidentified & 0 & 1 & 1 \\
\hline \multicolumn{4}{|l|}{ Snake identified by venom EIA: } \\
\hline$B$ atrox & 45 & 44 & 20 \\
\hline$B$ bilineatus & 25 & 27 & 16 \\
\hline$B$ taeniatus & 3 & 2 & 1 \\
\hline B brazili & 0 & 1 & 0 \\
\hline Lachesis muta & 1 & 2 & 0 \\
\hline
\end{tabular}

EIA=enzyme immunoassay.

*Numbers do not always sum to total because of missing data.

tives or friends of patients who had not been bitten in the past and were considered representative of the normal population within the study area. ${ }^{11}$ We froze residual plasma/serum from the blood clotting test for detection of specific venom antigen by enzyme immunoassay using the technique described by Ariaratnam et $\mathrm{al}^{12}$ but with an additional step before the wells were coated with antiserum. Four millilitres of each antiserum was passed over a CN-Br activated Sepharose 4B affinity column (Sigma, Poole, Dorset) to which was bound $5 \mathrm{mg}$ of each venom to retain as much venom specific antibody as possible. Enzyme immunoassays were developed for five different venoms ( $B$ atrox, $B$ bilineatus smaragdinus, $B$ taeniatus, $B$ brazili, and $L$ muta). This assay had been validated in a separate study by testing admission samples from 57 patients selected because all had brought in the dead snake (personal communication). Therapeutic antivenom concentrations were measured by enzyme immunoassay in 103 patients. $^{11}$

\section{Statistical analysis}

We constructed a database using Microsoft Access and compared the efficacy of antivenoms and reaction rates with $2 \times 3$ tables. The relation between the dose of antivenom required and the initial serum concentration of venom antigen was determined with the Kruskal-Wallis test.

\section{Results}

Randomisation and clinical features

We recruited 210 patients with incoagulable blood (fig 1). Eighty seven patients $(41.4 \%)$ received Colombian INS antivenom, 82

Table 2 Clinical features of envenoming in 210 patients bitten by snakes. All had incoagulable blood before randomisation to antivenom therapy*

\begin{tabular}{|c|c|c|c|}
\hline & Colombian $(n=87)$ & Brazilian $(\mathrm{n}=82)$ & Ecuadorian ( $n=41$ ) \\
\hline \multicolumn{4}{|l|}{ Local: } \\
\hline Pain & 76 & 79 & 37 \\
\hline Swelling & 70 & 75 & 33 \\
\hline Local lymphadenopathy & 27 & 26 & 10 \\
\hline Bleeding from bite site & 44 & 38 & 26 \\
\hline Erythema & 44 & 28 & 15 \\
\hline Blistering & 25 & 7 & 6 \\
\hline Ecchymosis & 27 & 26 & 13 \\
\hline \multicolumn{4}{|l|}{ Systemic: } \\
\hline Nausea & 38 & 33 & 16 \\
\hline Vomiting & 23 & 15 & 6 \\
\hline Fever $\left(>37.5^{\circ} \mathrm{C}\right)$ & 22 & 19 & 8 \\
\hline Syncope & 10 & 13 & 7 \\
\hline Gingival bleeding & 44 & 35 & 13 \\
\hline Blood in sputum/saliva/vomit & 37 & 34 & 9 \\
\hline Epistaxis & 12 & 15 & 4 \\
\hline Gross haematuria & 16 & 17 & 10 \\
\hline Bleeding skin/mucosa & 7 & 9 & 4 \\
\hline Blood in stool (melaena) & 7 & 9 & 4 \\
\hline
\end{tabular}

${ }^{*}$ Numbers do not always sum to total because of missing data. 


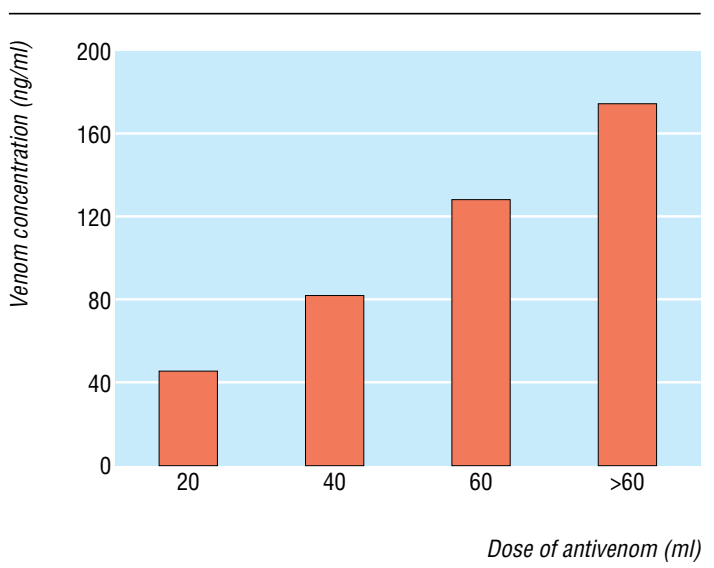

Fig 2 Relation between median serum concentrations of venom antigen on admission in patients requiring treatment with $20 \mathrm{ml}$ (two vials), $40 \mathrm{ml}$ (four vials), $60 \mathrm{ml}$ (six vials), and $>60 \mathrm{ml}$ of antivenom

$(39 \%)$ received Brazilian antivenom, but only 41 (19.5\%) received Ecuadorian antivenom because the supply ran out after the 140th patient (table 1). The groups of patients receiving the three different antivenoms were similar in all respects on admission to hospital and before they received treatment (tables 1 and 2). Table 2 shows the clinical features of recruited patients.

\section{Snakes responsible for bites}

Twenty nine patients (14\%) brought in the snake responsible for the bite: 13 (45\%) were identified as $B$ atrox, $12(41 \%)$ as $B$ bilineatus smaragdinus, $2(7 \%)$ as $B$ taeniatus, and $2(7 \%)$ remained unidentified (table 1). Specimens of $B$ atrox ranged from $20-90 \mathrm{~cm}$ (mean $43 \mathrm{~cm}$, SD $22 \mathrm{~cm}$ ) and B bilineatus 15-50 cm (34 cm, SD 14 $\mathrm{cm})$ and the two $B$ taeniatus specimens measured $150 \mathrm{~cm}$ and $180 \mathrm{~cm}$. With the help of herpetologists and the results of enzyme immunoassay we identified the snake responsible for envenoming in 187 (89\%) cases: 109 (58\%) were bitten by $B$ atrox, 68 (36\%) by B bilineatus, $6(3 \%)$ by $B$ taeniatus, 1 (1\%) by B brazili, and $3(2 \%)$ by $L$ muta. The distribution of bites by the different species was similar among the three groups (table 1).

\section{Venom antigen detection}

We assessed the serum concentrations of venom antigen from admission to discharge in 148 patients out of the 180 who received an initial dose of $20 \mathrm{ml}$ of antivenom (samples from 32 patients were lost during transport from Shell to Quito). Concentrations on admission correlated significantly with the total volume of antivenom required to restore blood coagulabil- ity permanently $(\mathrm{P}<0.0001)$. In the small group of patients who required more than $60 \mathrm{ml}$ of antivenom, median venom antigen concentrations were about fourfold to fivefold higher than those in patients who required only $20 \mathrm{ml}$ of antivenom (fig 2). The time to venom clearance was also longer in patients who required higher doses of antivenom (fig 3).

\section{Efficacy of antivenom treatment}

Two patients died. A 4 year old boy treated with Brazilian antivenom and a 38 year old woman treated with Colombian antivenom died 11 hours and 3 days, respectively, after being bitten by $B$ atrox. Both developed acute pulmonary oedema from which they could not be resuscitated. Ten patients $(5 \%$ in each treatment group) developed local necrosis. All other patients were well on discharge from hospital.

Table 3 gives details of the comparative efficacy of the antivenoms. One hundred and eighty patients were treated with an initial dose of $20 \mathrm{ml}$ (two vials). In those who received this dose of Colombian antivenom, blood coagulability was restored in $64 \%(46 / 72)$ at 6 hours compared with $49 \%(35 / 72)$ and $42 \%$ $(15 / 36)$ of those who received Brazilian and Ecuadorian antivenoms, respectively $(\mathrm{P}=0.054)$. Permanent restoration of coagulability was recorded within 24 hours after starting treatment in almost all patients given $20 \mathrm{ml}$ of Colombian antivenom $(64 / 65 ; 99 \%)$, in 60/67 (90\%) treated with the Brazilian antivenom, and in 32/35 (91\%) treated with the Ecuadorian antivenom. Colombian antivenom also proved superior when the initial dose was $<70 \mathrm{ml}$ and after any initial dose of antivenom (table 3). Eighty one patients (45\%) required more than one dose of antivenom, including 11 patients whose blood became incoagulable again after a normal result from the whole blood clotting test at 6 hours. There was no difference in median total doses of the three antivenoms.

\section{Therapeutic concentrations of antivenom}

Of the 103 patients in whom we measured serum concentrations of therapeutic antivenom, 63 had received an initial dose of 20 $\mathrm{ml}$ with or without subsequent doses. Antivenom was detectable in the serum when serum venom antigenaemia had become undetectable and for at least 48 hours, even in those who had received only a single dose of antivenom (fig 4 ).

\section{Antivenom reactions}

Early reactions to antivenom were common, including rash, vomiting, abdominal pain, fevers and chills, pruritis, and, more seriously, dyspnoea and hypotension. In those receiving an initial antivenom dose of $20 \mathrm{ml}$, reaction rates were 19\% (7/37) in those receiving Ecuadorian antivenom, 73\% (56/71) for Colombian,

Table 3 Permanent restoration of blood coagulability after various initial doses of antivenom at 6 and 24 hours after start of treatment

\begin{tabular}{|c|c|c|c|c|}
\hline \multirow[b]{2}{*}{ Initial dose } & \multicolumn{2}{|c|}{ At 6 hours } & \multicolumn{2}{|c|}{ At 24 hours } \\
\hline & No (\%) of patients & P value* & No $(\%)$ of patients & $P$ value ${ }^{*}$ \\
\hline \multicolumn{5}{|l|}{$20 \mathrm{ml}$} \\
\hline Brazilian & $35 / 72$ (47) & \multirow[t]{3}{*}{0.054} & 60/67 (90) & \multirow[t]{3}{*}{0.10} \\
\hline Colombian & $46 / 72(64)$ & & $64 / 65(99)$ & \\
\hline Ecuadorian & $15 / 36 \quad(42)$ & & $32 / 35(91)$ & \\
\hline \multicolumn{5}{|l|}{$<70 \mathrm{ml}$} \\
\hline Brazilian & $37 / 74 \quad(50)$ & \multirow[t]{3}{*}{0.045} & 60/68 (88) & \multirow[t]{3}{*}{0.06} \\
\hline Colombian & $48 / 74(65)$ & & $66 / 67$ (99) & \\
\hline Ecuadorian & $15 / 36 \quad(42)$ & & $32 / 35 \quad(91)$ & \\
\hline \multicolumn{5}{|c|}{ Any initial dose } \\
\hline Brazilian & $41 / 81 \quad(51)$ & \multirow[t]{3}{*}{0.012} & $66 / 75(88)$ & \multirow[t]{3}{*}{0.16} \\
\hline Colombian & $59 / 87(68)$ & & $77 / 80$ (96) & \\
\hline Ecuadorian & $17 / 40(43)$ & & $36 / 39(92)$ & \\
\hline
\end{tabular}

${ }^{*}$ For comparison of Colombian antivenom with others. 

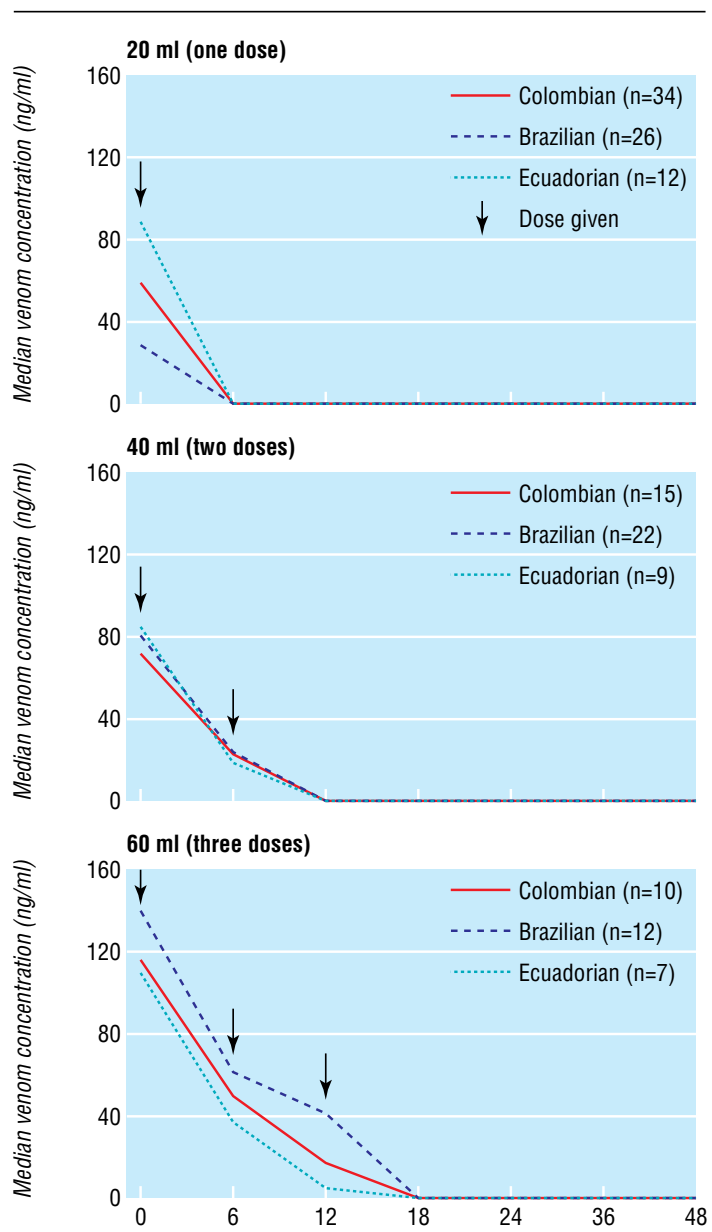

Time after antivenom (hours)

Fig 3 Clearance of venom antigen from 148 patients treated with one dose (venom antigen completely cleared by all three antivenoms within 6 hours of start of antivenom); two doses (venom antigen completely cleared from circulation within 12 hours after start of antivenom in patients whose coagulopathy did not respond to initial $20 \mathrm{ml}$ dose); and three doses (venom antigen finally completely cleared from circulation within 18 hours after start of antivenom in patients whose coagulopathy did not respond to first two $20 \mathrm{ml}$ doses)

and 53\% (37/70) for Brazilian antivenom. These rates were significantly different from each other $(\mathrm{P}<0.0001)$. Two patients who developed hypotension had been treated with Colombian antivenom, one with Brazilian antivenom, and one with Ecuadorian antivenom.

\section{Discussion}

In this randomised double blind comparative trial of three polyspecific antivenoms in 210 patients with venom induced coagulopathy, the resolution of coagulopathy at 6 and 24 hours after the initial dose were the primary end points. We chose the 6 hour time interval because of the frequently reported observation that, in envenomed patients, blood coagulability is usually restored within 3-6 hours of the administration of a dose of antivenom sufficient to neutralise circulating procoagulant toxins. $^{13-18}$ If an initial two vials $(20 \mathrm{ml})$ of antivenom failed to correct the coagulopathy within 6 hours, a further two vials were given. Judged by this criterion, Colombian antivenom proved the most effective.
We could not detect any difference in the ability of the three antivenoms to eliminate or reduce local effects of envenoming. Only 10 patients $(5 \%)$ developed local necrosis, the main cause of persistent morbidity in those who survive severe envenoming. The pathophysiology of local envenoming may involve direct and indirect inflammatory mechanisms that are independent of neutralisation of venom toxins mediated through antivenom. ${ }^{19-22}$

The high incidence of symptoms of early anaphylactoid reactions (including rash, vomiting, abdominal pains, fevers, chills, pruritis, dypnoea, and hypotension) in our patients was reminiscent of results of a study in Brazil in which reaction rates as high as $84 \%$ were recorded..$^{13}$ In other studies, early reaction rates ranged from $3 \%$ to $54 \%{ }^{23-25}$ Among 178 patients who could be closely monitored, $100(56 \%)$ suffered early reactions. The antivenoms differed significantly in their rates of reaction (Ecuadorian 19\%, Brazilian 53\%, Colombian 73\%, P<0.0001). The higher reactogenicity of Colombian antivenom may reflect its higher protein content $(61 \mathrm{mg} / \mathrm{ml})$ compared with the two other antivenoms (Ecuadorian $47 \mathrm{mg} / \mathrm{ml}$, Brazilian $44 \mathrm{mg} / \mathrm{ml})^{5}$ and
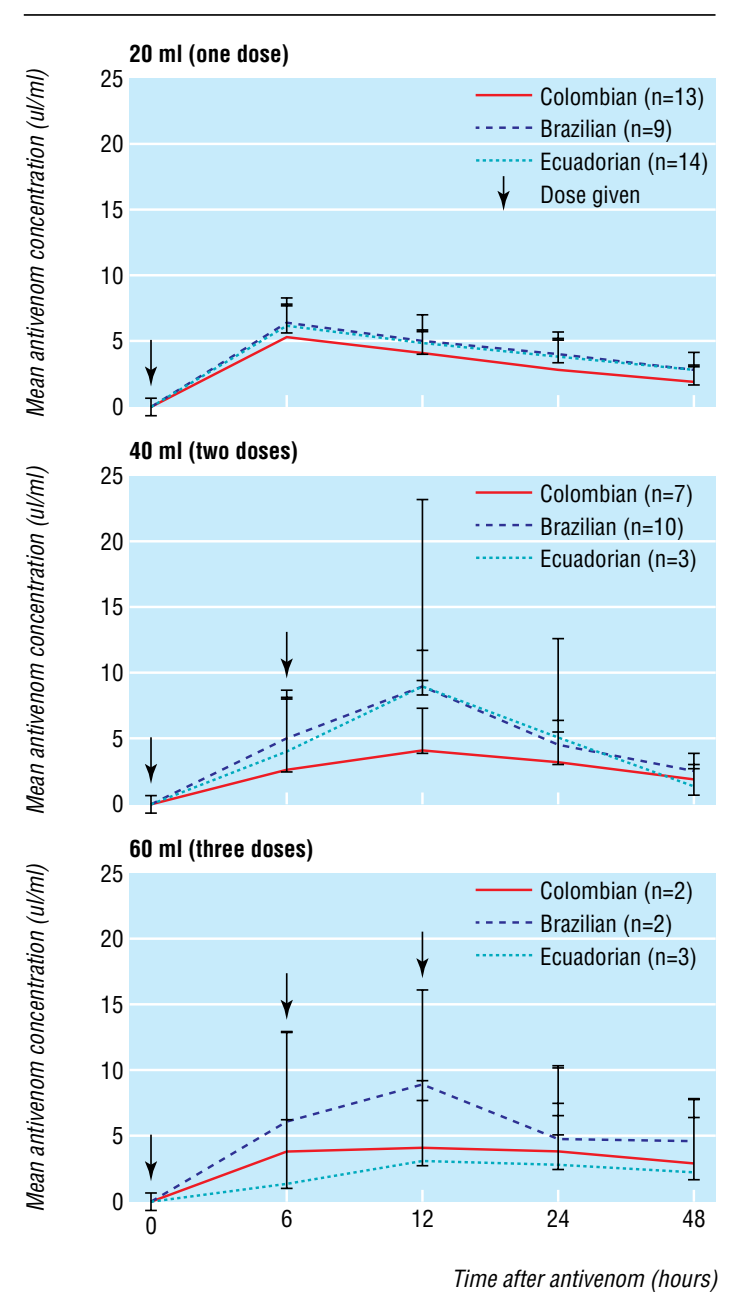

Fig 4 Therapeutic antivenom concentrations in 63 patients according to dose of antivenom on admission: one dose (antivenom clears venom from the circulation within 6 hours after start of antivenom; antivenom concentrations are maximum at 6 hours and remain high for more than two days); two doses (antivenom clears venom within 12 hours from start of first dose of antivenom; antivenom concentrations are maximum at 12 hours); and three doses (antivenom clears venom within 18 hours from start of first dose of antivenom; antivenom concentrations are maximum at 12 hours). Results are means (2 SE) showing overlapping error bars at each time point 
the fact that it is a whole IgG ammonium sulphate precipitated preparation, whereas the other two antivenoms are pepsin digested $\mathrm{F}\left(\mathrm{ab}^{\prime}\right)_{2}$ fragments. ${ }^{5}$ Severe reactions were rare and were promptly reversed by use of adrenaline, antihistamines, and corticosteroids.

Enzyme immunoassay was useful for identifying the snake responsible for envenoming. Concentrations of venom antigen on admission correlated with the severity of envenoming, as in studies of envenoming by Vipera aspis, ${ }^{26} \mathrm{~B}$ lanceolatus, ${ }^{27}$ and Daboia siamensis. ${ }^{28}$ Patients whose venom antigenaemia was relatively low required treatment with only two vials $(20 \mathrm{ml})$ of antivenom, whereas those with higher levels needed repeated doses of antivenom. Venom clearance by antivenom occurred more rapidly in patients with lower venom antigenaemias on admission, as in patients bitten by $B$ jararaca. ${ }^{29}$

$B$ atrox and $B$ bilineatus smaragdinus are responsible for most snake bites in the Pastaza region. $B$ atrox is notorious as the leading cause of severe snake bites wherever it occurs in South America. ${ }^{4}{ }^{16}$ In contrast, $B$ bilineatus, a distinctive bright green arboreal snake, is less well known as a snake of real medical importance. ${ }^{30}$ In this study $36 \%$ of our patients were bitten by this species and $6 \%$ by $B$ taeniatus, $B$ brazili, and $L$ muta. Other crotalines including $B$ pulcher (formerly $B$ albocarinatus and also known as Bothriopsis pulchra), Bothrocophias (formerly Bothrops and Porthidium) hyoprora, and Bothrocophias microphthalmus are known to inhabit this area of unusual diversity of venomous snakes. ${ }^{4}$

\section{Conclusions}

All three of the tested antivenoms were clinically adequate in eastern Ecuador. Colombian antivenom, however, was the most effective judged by speed and efficiency in permanently correcting venom induced coagulopathy. The Ecuadorian antivenom was significantly less likely than either of the other two antivenoms to cause early anaphylactoid reactions. We recommended that the Ecuadorian Ministry of Health should increase production of this antivenom or, failing that, import either Colombian or Brazilian antivenoms to improve the treatment of snake bite envenoming in the Ecuadorian Amazon region.

We thank the staff (medical, administrative, nursing, and technical) of Hospital Vozandes del Oriente, Shell, Pastaza; I Hastings (statistical advice) and A Richards (technical help), Liverpool School of Tropical Medicine; and the Ecuadorian Ministry of Health. We thank Philip Cooper, Hospital Vozandes, Quito, who arranged the transport of specimens from Ecuador to Liverpool.

Contributors: DAW and RDGT conceived, planned, and wrote up the study with help from SM, ME, and DGL. RS, JC, BLM, SM, JM, BQ, GH, and SN contributed to the design of the study, treated the patients, and collected appropriate samples. NB organised the collection and labelling of the samples, and GDL performed the immunoassays. ME designed the database, and DGL extracted the data and performed the statistical calculations. MEB was responsible, with DAW, for the identification of the snakes and with DAW and RDGT for obtaining the venom used for EIA studies. DD, working in Shell hospital, collected data from the patients' records. GR was responsible for coordination of the project with the Ecuadorian Ministry of Health. DAW is guarantor.

Funding: European Union (contract No ERBIC18-CT96-0032). The Instituto Butantan (San Paulo, Brazil), the Instituto Nacional de Salud (Bogota, Colombia), and the Instituto Nacional de Higiene y Medicina Tropical (Guayaquil, Ecuador) donated the antivenoms.

Competing interest: None declared.

Ethical approval: Ecuadorian Ministry of Health and Hospital Vozandes del Oriente, Shell, Pastaza, Ecuador.

1 Swaroop S, Grab B. Snake bite mortality in the world. Bull World Health Org 1954;10:35-76.

2 Kerrigan KR. Venomous snakebite in eastern Ecuador. Am J Trop Med Hyg $1991 ; 44: 93-9$

\section{What is already known on this topic}

Most studies on effectiveness of antivenom in snake bite have been carried out by estimating neutralising potency in experimental animals

Few well designed clinical trials have been carried out on the treatment of human snake bite in the rural tropics

\section{What this study adds}

A simple, accurate, and robust whole blood clotting test can be used to assess the ability of three antivenoms (Brazilian, Colombian, and Ecuadorian) to eliminate venom induced coagulopathy permanently

Enzyme immunoassay enabled the accurate identification of the snake species responsible for envenoming

Although the Colombian antivenom proved the most effective, all three antivenoms proved suitable for treating snakebite victims in this region

The Brazilian and Colombian antivenoms caused a high incidence of anaphylactoid reactions. This should prompt their manufacturers to improve production procedures

3 Touzet JM. Mordeduras de ofidios venenosos en la comunidad de los indigenas SionaTouzet JM. Mordeduras de ofidios venenosos en la comunidad de los indigenas SionaSecoya de San Pablo de Kantesyia y datos sobre la fauna de reptiles
Publicaciones Museo Ecuatoriano de Ciencias Naturales 1986;5:163-90.

4 Warrell DA. Snakebites in Central and South America: epidemiology, clinical features, and clinical management. In: Campbell JA, Lamar WW, eds. The venomous reptiles of the western hemisphere. Vol 2. New York: Cornell University Press, 2004:709-62.

5 Theakston RDG, Laing GD, Fielding CM, Freire Lascano A, Touzet J-M, Vallejo F, et al. Treatment of snake bites by Bothrops species and Lachesis muta in Ecuador: laboratory screening of candidate antivenoms. Trans $R$ Soc Trop Med Hyg 1995;89:550-4.

6 Campbell JA, Lamar WW. The venomous reptiles of the western hemisphere. New York: Cornell University Press, 2004

7 Warrell DA, Davidson NMcD, Greenwood BM, Ormerod LD, Pope HM, Watkins BJ, et al. Poisoning by bites of the saw-scaled or carpet viper (Echis carinatus) in Nigeria. $Q J$ Med 1977:46:33-49.

8 Sano-Martins IS, Fan HW, Castro SCB, Tomy SC, França FOS, Jorge MT, et al. Reliability of the simple 20 minute whole blood clotting test (WBCT20) as an indicator of low plasma fibrinogen concentration in patients envenomed by Bothrops snakes. Toxicon 1994;32:1045-50.

9 Theakston RDG, Warrell DA. Antivenoms: a list of hyperimmune sera currently available for the treatment of envenoming by bites and stings. Toxicon 1991;29:1419-70.

10 Reid HA. Venomous bites and stings. Medicine 1978;3:341-6.

11 Theakston RDG, Fan HW, Warrell DA, Dias da Silva WD, Ward SA, Higashi HG. Use of enzyme immunoassays to compare the efficacy and assess dosage regimens of three Brazilian Bothrops antivenoms. Am J Trop Med Hyg 1992;47:593-604.

12 Ariaratnam CA, Sjöstrom L, Raziek Z, Kularatne SAM, Kodikara RWK, Sheriff MHR, et al. An open, randomised comparative trial of two antivenoms for the treatment of al. An open, randomised comparative trial of two antivenoms for the treatment of
envenoming by Sri Lankan Russell's viper (Daboia russelii russelii). Trans $R$ Soc Trop envenoming by Sri Lanka
Med Hyg 2001;95:74-80.

13 Cardoso JLC, Fan HW, França FOS, Jorge MT, Leite RP, Nishioka SA, et al. Randomized comparative trial of three antivenoms in the treatment of envenoming by lance-headed vipers (Bothrops jararaca) in São Paulo, Brazil. QJ Med 1993;86:315-25.

14 Jorge MT, Cardoso JLC, Castro SCB, Ribeiro L, França FOS, Sbroglio de Almeida ME, et al. A randomised blinded comparison of two doses of antivenom in the treatment of Bothrops envenoming in São Paulo, Brazil. Trans R Soc Trop Med Hyg 1995;89:111-4.

15 Otero R, Cardoso JLC, Higashi HG, Nunez V, Diaz A, Toro MF, et al. A randomised, blinded, comparative trial of one pepsin-digested and two whole IgG antivenoms for Bothrops snake bites in Uraba, Colombia. Am J Trop Med Hyg 1998;58:183-9.

16 Pardal PP, Souza SM, de Cassia da Costa Monteiro MR, Fan HW, Cardoso JLC, França FOS, et al. Clinical trial of two antivenoms for the treatment of snake bites in the eastFOS, et al. Clinical trial of two antivenoms for the treatment of snake bites
ern Amazon region of Brazil. Trans R Soc Trop Med Hyg 2004;98:28-42.

ern Amazon region of Brazil. Trans R Soc Trop Med Hyg 2004;98:28-42.
17 Phillips RE, Theakston RDG, Warrell DA, Galagadera Y, Abeysekera DTDJ, Dissanayake P, et al. Paralysis, rhabdomyolysis and haemolysis caused by bites of Russell's viper (Vipera russelli pulchella) in Sri Lanka: failure of Haffkine antivenom. QJ Med 1988;68:691-716.

18 Warrell DA, Looareesuwan S, Theakston RDG, Phillips RE, Chanthavanich P, Virivan C, et al. Randomized comparative trial of three monospecific antivenoms for bites by the Malayan pit viper (Calloselasma rhodostoma) in southern Thailand: clinical and laboratory correlations. Am J Trop Med Hyg 1986;35:1235-47.

19 Chaves F, Barboza M, Gutierrez JM. Pharmacological study of edema induced by venom of the snake Bothrops asper (terciopelo) in mice. Toxicon 1995;33:31-9.

20 Farsky SHP, Walber J, Coista-Cruz M, Cury Y, Teixera CF. Leukocyte response induced by Bothrops jararaca crude venom: in vivo and in vitro studies. Toxicon 1997;35:185-93. 21 Trebien HA, Calixto JB. Pharmacological evaluation of rat paw edema induced by Bothrops jararaca venom. Agents Actions 1989;26:292-300. 
22 Laing GD, Clissa PB, Theakston RDG, Moura-da-Silva A, Taylor MJ. Inflammatory pathogenesis of snake venom metalloproteinase-induced skin necrosis. Eur J Immunol 2003;33:3458-63

23 Fan HW, Marcopito LF, Cardoso JLC, França FOS, Malaque C, Ferrari RA, et al Sequential randomised and double blind trial of promethazine prophylaxis agains early anaphylactic reactions to antivenom Bothrops snake bites. BMJ 1999;318:1451-3

24 Malasit P, Warrell DA, Chanthavanich AP, Virivan C, Mongkolsapaya J, Singhthong B, et al. Prediction, prevention and mechanism of early (anaphylactic) antivenom reactions in victims of snake bites. $B M J$ 1986;292:17-20.

25 Otero R, Gutiérrez JM, Nunez V, Robles A, Estrada R, Segura E, et al. A randomised double-blind clinical trial of two antivenoms in patients bitten by Bothrops atrox in Colombia. Trans R Soc Trop Med Hyg 1996;90;696-700.

26 Audebert F, Sorkine M, Bon C. Envenoming by viper bites in France: clinical grading and biological quantification by ELISA. Toxicon 1992;30:599-609.

27 Bucher B, Canonge D, Thomas L, Tyburn B, Robbe-Vincent A, Choumet V, et al. Clinical indicators of envenoming and serum levels of venom antigens in patients bitten by Bothrops lanceolatus in Martinique, research group on snake bites in Martinique. Tran R Soc Trop Med Hyg 1997;91:186-90.

28 28. Tun-Pe, Ba-Aye, Aye-Aye-Myint, Tin-Nu-Swe, Warrell DA. Bites by Russell's vipers (Daboia russelii siamensis) in Myanmar: effect of the snake's length and recent feeding on venom antigenaemia and severity of envenoming. Trans $R$ Soc Trop Med Hyg 1991;85:804-8.

29 França FOS, Barbaro KC, Fan HW, Cardoso JLC, Sano-Martins IS, Tomy SC, et al. Envenoming by Bothrops jararaca in Brazil: association between venom antigenaemia and severity on admission to hospital. Trans $R$ Soc Trop Med Hyg 2003;97:312-7.

30 Silva-Haad JJ. Las serpentes del género Bothrops en la Amazonia colombiana. Comando Unificado del Sur, Amazonia 1982;82:45-50.

bmj.com 2004;329:1129
Hospital Vozandes del Oriente, Shell, Pastaza, Ecuador Roger Smalligan hospital director

Judy Cole

Narcissa Brito senior hospital technician

Bruce L Mertz clinician

Steven Manock clinician

Jeffrey Maudlin clinician

Brad Quist clinician

Gary Holland clinician

Stephen Nelson clinician

Alistair Reid Venom Research Unit, Liverpool School of Tropical Medicine,

Liverpool L3 5QA

Gavin D Laing research scientist

David G Lalloo clinical senior lecturer

R David G Theakston professor of medical biology

Ministry of Health, Guayaquil, Ecuador

Gonzalo Rivadeneira doctor

Fundacion Herpetologica Gustavo Orcés, Quito, Ecuador

Maria Elena Barragan herpetologist

Nuffield Department of Clinical Medicine, University of Oxford, John Radcliffe Hospital, Headington, Oxford OX3 9DU

Daniel Dolley human biology student

Michael Eddleston Wellcome Trust career development fellow

David A Warrell professor of tropical medicine and infectious diseases

Correspondence to:D A Warrell david.warrell@clinical-medicine.oxford.ac.u 